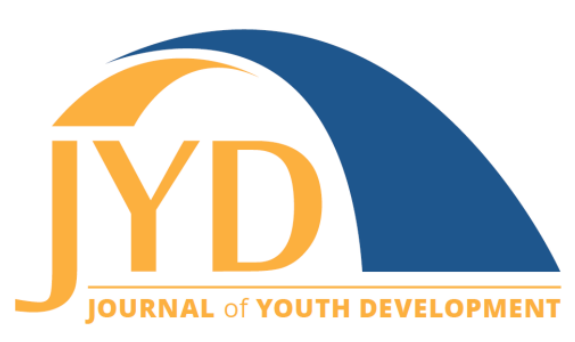

http://jyd.pitt.edu/ | Vol. 15 Issue 4 DOI 10.5195/jyd.2020.742 | ISSN 2325-4017 (online)

\title{
Are Volunteers Competent in Positive Youth Development? Perceptions From Three Stakeholder Groups
}

\author{
Dustin Homan \\ Ohio State University Extension, 4-H Youth Development \\ homan3@purdue.edu \\ Hannah K. Epley \\ Ohio State University Extension, 4-H Youth Development \\ epley.24@osu.edu \\ Kirk L. Bloir \\ Ohio State University Extension, 4-H Youth Development \\ bloir.1@osu.edu
}

\begin{abstract}
Some youth organizations entrust adult volunteers with delivering programs and forging relationships with youth clientele. As a result, volunteers should be competent in certain knowledge, skills, and abilities that catalyze positive youth development processes to occur. This research expands upon the results of an initial study designed to address shortcomings of a volunteer competency framework. Our objective for this study was to assess and compare the discrepancies between importance and ability-to-perform ratings of adult volunteers across 6 competency areas from the Volunteer Research Knowledge Competency Taxonomy. Over 10,000 youth professionals, adult volunteers, and families of youth members responded to an online survey. Respondents rated the importance of, and volunteers' performance in the 6 competency areas; they also provided input about the modalities they preferred for delivering training and resources. Performance means varied across the 3 groups: Volunteers' overall performance means were the highest, followed by families, and then professionals. Mean weighted discrepancy scores were calculated to compare the importance and performance rankings across respondent groups. Based on the scores, future volunteer trainings and resources should be prioritized around the competency areas of organization, positive youth development, program management, and communication. Volunteers also preferred more self-directed approaches for future trainings. Results from this study suggest that the volunteer competency taxonomy is still a valid framework and affirms other youth worker competency frameworks. The results also help establish a baseline of data that can be used to see if future training interventions and resources are perceived as effective.
\end{abstract}

Key words: volunteer management, competency, performance, training

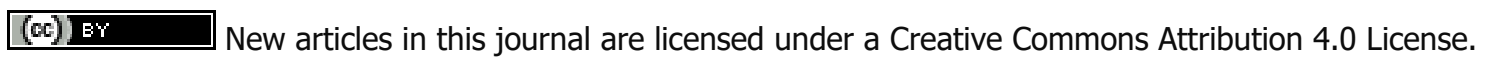
This journal is published by the University Library System, University of Pittsburgh and is cosponsored by the University of Pittsburgh Press. The Journal of Youth Development is the official peer-reviewed publication of the National Association of Extension 4-H Youth Development Professionals and the National AfterSchool Association. 


\section{Perceptions of Volunteer Competence}

\section{Introduction}

Organizations serving youth differ in their approaches. However, they coalesce around a common mission of helping youth acquire developmental assets of competence, caring, character, connection, and confidence; reducing their involvement in risky behaviors; and ultimately becoming contributing global citizens (Guerra \& Bradshaw, 2008; Lerner et al., 2013).

Practically delivering this mission occurs at the point-of-service: "the place where youth and program intersect" (Smith et al., 2006, p. 94). These intersections may include activities such as facilitated workshops; community service events; experiential, self-guided projects; group or club meetings; and mentorship from adults. Positive youth development (PYD) is more likely to occur when these intersections are intentionally designed with specific features. These features include clear and consistent structure and appropriate supervision, and supportive relationships (Benson, 2007; Eccles \& Gootman, 2002).

Some youth organizations entrust unpaid adult volunteers with delivering programs and forging caring relationships with youth clientele at the point-of-service. As a result, volunteers become the primary interface between the youth with the organization and vice versa. Youths' perceptions of the organization, their satisfaction, and their likelihood of remaining involved in the organization are all influenced by their relationships with adult volunteers (Albright \& Ferrari, 2010). Therefore, point-of-service quality, and a youth organization's ability to achieve its desired outcomes and impacts, depends on recruiting volunteers who can be trusted and trained to be competent in PYD principles (Astroth et al., 2004; Fogarty et al., 2009).

\section{Competencies}

Identifying adults with specific, desired interpersonal characteristics and training them to be proficient in facilitating programs and environments that can promote positive youth development outcomes can be daunting. One answer to this challenge is to use a competency framework as a guide. Competencies are essential knowledge, skills, and abilities that adults who work with youth need to possess and be able to carry out in order to achieve programmatic outcomes (Shippmann et al., 2000).

Competencies have been proposed as a way to move towards a more formal level of professionalism in the field of youth development, as well as associated with supporting desired 


\section{Perceptions of Volunteer Competence}

positive youth outcomes (Astroth et al., 2004). Studies of 4-H volunteers support the relationship between adult competence and the life skills that youth learn. Significant positive relationships were identified between adult volunteers' self-perceived performance across specific competencies and their perceptions of skills learned by youth (Radhakrishna \& Ewing, 2011; Singletary et al., 2006).

Competency frameworks for youth development workers have been proposed by Yohalem (2003); Astroth et al. (2004); the National AfterSchool Association (2011); and 4-H National Headquarters (2017). Some common competencies among these frameworks include

- designing activities and creating safe learning environments appropriate for youth at different stages of growth and development;

- understanding and incorporating positive youth development theories, trends, and research;

- building relationships with and engaging partners, including parents, volunteers, and community members;

- cultural competency and inclusive programming;

- evaluation and program improvement; and

- professional development.

\section{Volunteer Competencies.}

The aforementioned frameworks were designed specifically for youth development workers. These are people who are likely employed by a youth organization and compensated for their time. They may have formal training in a youth-related field and are expected to engage in continuous, professional development. But how do these competencies relate to organizations who also engage unpaid volunteers who may or may not have formal training in and experience with youth?

We found only one competency framework specifically designed for youth volunteers: the Volunteer Research Knowledge and Competency Taxonomy (VRKC). The VRKC was designed for adults who volunteer their time with the 4-H organization without expectation of pay. The competencies were determined through a national survey of volunteers, youth development professionals, and state specialists by Culp and colleagues (2007). The VRKC includes six recommended competency domains that adult 4-H volunteers should possess; they are presented in Table 1. 
Table 1. Volunteer Research Knowledge Competency (VRKC) Taxonomy Adopted by the National 4-H Council (n.d.-b)

\begin{tabular}{|c|c|}
\hline Competency taxonomy & Definition and examples \\
\hline Communication & $\begin{array}{l}\text { Ability to create, deliver, and understand information. } \\
\text { Examples: good speaking, listening, and writing skills; positively } \\
\text { presenting 4-H to the public; and appropriately using technology to } \\
\text { communicate. }\end{array}$ \\
\hline Organization & $\begin{array}{l}\text { Ability to engage others in planning and delivering programs. } \\
\text { Examples: planning and organizing successful programs, recruiting } \\
\text { and involving parents in 4-H activities, and identifying and serving } \\
\text { community needs. }\end{array}$ \\
\hline 4-H program management & $\begin{array}{l}\text { Ability to understand and follow appropriate policies, procedures, } \\
\text { and safety guidelines. } \\
\text { Examples: anticipating and managing risks, keeping accurate and } \\
\text { complete records and finances, and providing an organized and } \\
\text { supervised club environment. }\end{array}$ \\
\hline $\begin{array}{l}\text { Positive youth development } \\
\text { (PYD) }\end{array}$ & $\begin{array}{l}\text { Ability to create an environment that results in the positive } \\
\text { development of youth. } \\
\text { Examples: caring for and the ability to motivate youth, helping } \\
\text { youth to develop life and leadership skills, appreciating diversity. }\end{array}$ \\
\hline Education design and delivery & $\begin{array}{l}\text { Ability to plan, conduct, and evaluate learning opportunities for } \\
\text { youth. } \\
\text { Examples: presenting activities and programs appropriate for } \\
\text { different ages, using a variety of activities for different learning } \\
\text { styles, and having knowledge of the topics/subject matter } \\
\text { delivered. }\end{array}$ \\
\hline Interpersonal characteristics & $\begin{array}{l}\text { Ability to work effectively with and understand others. } \\
\text { Examples: volunteer is honest, ethical, and moral; volunteer has } \\
\text { patience and is flexible; volunteer has compassion for others. }\end{array}$ \\
\hline
\end{tabular}

All of the VRKC competency taxonomies can be linked to similar competencies in the youth development workers' frameworks presented earlier. However, the VRKC competencies are more specific to the execution of programming at the local level rather than more strategic tasks expected of youth professionals. For example, a youth professional exhibits competence in risk management by setting and enforcing policies, procedures, and guidelines, while a 


\section{Perceptions of Volunteer Competence}

volunteer exhibits competence in risk management by following the policies, procedures and guidelines imposed by the professional. 4-H National Headquarters' (2017) professional competencies also contain an entire domain about building and maintaining a volunteer program that is not present in the VRKC.

\section{The Research Need}

The VRKC was designed as a tool for youth development professionals to use in guiding their selection, orientation, and education of adult volunteers. Yet, we believe the taxonomy had shortcomings. The VRKC had not been reassessed for nearly 10 years and there was a lack of published research related to it. Additionally, parents/guardians/adult family members of 4-H members (hence forth referred to as families), a key stakeholder group, were not consulted as part of the original methodology used to create the VRKC. Using the taxonomy as a guide for training could also be a daunting challenge for youth development professionals as they try to determine which competencies to begin with.

We conducted an initial study to investigate some of the aforementioned shortcomings. Specifically, our objective was to explore and compare perceptions of three stakeholder groups (i.e., county 4-H professionals, 4-H adult club volunteers, and families of 4-H club members) about the importance of the competencies as identified in the VRKC. High importance averages reported for all competencies, combined with affirming qualitative comments, led us to conclude that the VRKC should continue to be used in the context of 4- $\mathrm{H}$ to identify, train, and evaluate volunteers (Homan et al., 2017). Because all of the competency taxonomies in our initial study received high importance ratings, we desired an additional analysis to help us better understand how volunteers are performing across the competencies, and in order to prioritize them.

\section{Objective}

Our objective for this study was to assess and compare the discrepancies between importance and ability to perform ratings of Ohio $4-\mathrm{H}$ professionals, 4-H club volunteers, and families of 4-H club members in order to identify and prioritize training needs. We also sought input from our respondents about the modalities they preferred for training related to the competencies to be delivered. 


\section{Perceptions of Volunteer Competence}

Better understanding how stakeholders perceive volunteers' abilities to perform the competencies might reveal gaps not previously seen in the importance data. Low performance ratings suggest topics that should be prioritized and made the focus of future training topics and resources.

\section{Methodology}

\section{Design}

Our original research study was a descriptive, cross-sectional study using a mixed-methods design through an online survey. Thirteen county and state 4- $\mathrm{H}$ professionals and four 4- $\mathrm{H}$ volunteers and family members reviewed the survey for face and content validity and provided us with feedback. We uploaded the survey into Qualtrics for distribution. Qualtrics is an online platform for the creation and distribution of surveys, along with collection, analysis, and reporting of data from respondents taking the survey. This study was approved by The Ohio State University Behavioral and Social Science Institutional Review Board Protocol 2016 E0699.

\section{Procedure}

Dillman's (2000) tailored research design guided how we administered the survey. We sent prenotification and invitation emails through Qualtrics, along with three email reminders to participants who had not completed the survey. The survey was open for 23 days in December 2016.

\section{Participants}

Three groups of participants from across the state participated in the survey: county 4-H professionals; 4-H volunteers; and parents, guardians, and adult family members of 4-H members. A link to complete the survey was emailed to all 4-H professionals, and volunteers and family members with e-mail addresses in 4HOnline, an online management system. Approximately $93 \%$ of all volunteers and families in the 4 HOnline system provided email addresses. All email addresses were first imported into Microsoft Excel where duplicates were removed before the survey was sent (e.g., some $4-\mathrm{H}$ volunteers are also family members of $4-\mathrm{H}$ members) to prevent participants from responding to the survey twice. Table 2 displays survey data from 10,771 responses received for an overall response rate of $24.4 \%$. 


\section{Perceptions of Volunteer Competence}

Table 2. Survey Response Rates

\begin{tabular}{|l|c|c|c|c|}
\hline Respondent group & $\begin{array}{c}\text { Population } \\
\text { with emails }\end{array}$ & $\begin{array}{c}\text { Bounced emails } \\
\text { \& opted out }\end{array}$ & Responses & Response rates \\
\hline Families & 33,795 & $2,469(7 \%)$ & 5,905 & $18.85 \%$ \\
\hline Volunteers & 13,307 & $621(5 \%)$ & 4,753 & $37.46 \%$ \\
\hline 4-H Professionals & 144 & 0 & 113 & $78.47 \%$ \\
\hline Total & 47,246 & 3,090 & 10,771 & $24.39 \%$ \\
\hline
\end{tabular}

Eight volunteer respondents listed their age under 18 years. Their age data were labeled as missing data, and we assumed their responses were typos because only volunteers over the age of 18 are in the $4 \mathrm{HOnline}$ system and received the survey link. One hundred family member respondents listed their age under 18 years. We believed some of these entries may have been typos, but these cases were excluded from the analysis because we could not guarantee that the survey had been completed by a family member or guardian over the age of 18 and not a child.

A majority of the participants identified as female and white, which is reflective of our state 4-H organization's demographics. A majority of respondents indicated they were involved with 4-H when they were young. The mean years of involvement with 4-H reported by participants were: 7.3 years for families, 11.6 years for volunteers, and 11.8 years for professionals.

\section{Instrumentation}

Our survey collected quantitative ratings about participants' perceived importance of and volunteers' performance across the six VRKC competency taxonomies using 5-point Likert-type scales. Additionally, demographic data and training preferences were also collected.

County 4-H professionals were asked to provide an average rating of their entire county 4-H volunteers' performance as a group in each of the six competency domains. Family members were asked to provide a rating of their youth's 4-H club volunteers' performance. 4-H volunteers were asked to provide a rating of how well they believed they performed in each of the domains.

The response scale for importance ranged from 1 (not important) to 5 (very important) and consisted of six items (i.e., the six competency domains). For example, we asked all 


\section{Perceptions of Volunteer Competence}

respondents, "How important are county 4-H volunteers' abilities to create, deliver, and understand information? Examples: Good speaking, listening, and writing skills; positively presenting 4-H to the public; appropriately using technology to communicate."

The response scale for performance ranged from 1 (very poor) to 5 (very good) and consisted of six items. For example, we asked family respondents, "How would you rate your youth's 4-H volunteers' abilities to engage others in planning and delivering programs? Examples: Planning and organizing successful programs; recruiting and involving parents in 4-H activities; identifying and serving community needs."

Demographic data were also gathered. Finally, we asked respondents how we could better equip 4-H volunteers with the knowledge, skills, and abilities they needed through different training modalities. Respondents could select multiple answers from a pre-generated list of six items (e.g., host in-person trainings, provide access to online training modules, etc.) or provide their own ideas (i.e., qualitative data) in a text box.

\section{Validity and Rigor}

We compared early respondents to later respondents as a recommended way of reducing concerns of nonresponse error since non-respondents are perhaps similar to late respondents (Miller \& Smith, 1983; Radhakrishna \& Doamekpor, 2008). Independent samples $t$-tests (equality of means with equal variances assumed) were analyzed to compare early and late responses. Only one of the 12 variables was significant at the 0.05 level for the family responses (education design and delivery performance at $p=.047$ ), and one for the volunteer responses (4-H program management performance at $p=.016)$. The late responder analysis lent confidence to the generalizability of our results.

Some participants without email or valid email addresses, access to internet access, or lacking computer literacy were excluded from our survey. However, over $85 \%$ of each population is believed to have received the survey, which lent additional confidence in our generalizing results to the Ohio $4-\mathrm{H}$ volunteer and family populations (93\% of both populations had email addresses in 4HOnline, but some surveys bounced back because the emails were incorrect; see Table 2).

Collecting data from three sources helped to ensure valid measurement of the concepts of interest through triangulation. Finally, youths' voices were also excluded from this survey. While 


\section{Perceptions of Volunteer Competence}

we believe youth are important stakeholders, they may not have the maturity to appropriately judge characteristics necessary to promote their own development (Homan et al., 2017).

One researcher coded and categorized the qualitative data of other ideas, which was crosschecked by another researcher-a form of observer triangulation to achieve inter-subjective agreement (Padgett, 2008). Additionally, we employed peer debriefing by all three of us meeting to review and discuss the codes and categories in order to reduce researcher bias (Padgett, 2008).

\section{Analysis}

We analyzed the quantitative data with Qualtrics, SPSS Statistics, and Microsoft Excel to calculate number of responses, means, standard deviations, and independent samples $t$-tests. Qualitative responses were downloaded into Microsoft Excel for coding and categorization.

We calculated mean weighted discrepancy scores (MWDS) by using the importance and performance means in order to compare competencies across respondent groups (see Figure 1). This score is an indication of areas of knowledge, skills, and abilities that may or may not need to be targeted through programmatic interventions (Borich, 1980). A higher MWDS signals where a disagreement exists between the importance of a competency and how well the competency is performed by volunteers. In other words, a higher MWDS means the competency was deemed important for a 4-H volunteer to know or possess, but they do not have adequate ability to perform it. These perceived gaps between current and desired performance can then be remedied through both training and non-training interventions and resources (Hobbs, 2012).

Figure 1. Steps to Calculating Mean Weighted Discrepancy Scores: The Borich Model

Step 1: (Importance mean - Performance mean) = Performance Discrepancy Score

Step 2: Performance Discrepancy Score $\times$ Importance mean $=$ Mean Weighted Discrepancy Score 
Journal of Youth Development | http://jyd.pitt.edu/ | Vol. 15 Issue 4 DOI 10.5195/jyd.2020.742

Perceptions of Volunteer Competence

\section{Results}

Tables 3 through 5 report descriptive statistics by respondent group for both importance and performance rankings of volunteers. The competencies are listed in the tables by descending MWDS.

Importance averages for all competencies were greater than 4.00 across all three groups based on a 5-point Likert-type scale, as previously reported in Homan et al. (2017). Respondents believed it was important or very important for volunteers to possess each of the six competencies.

Table 3. 4-H Professionals' Importance and Performance Scores

\begin{tabular}{|l|c|c|c|c|c|c|c|}
\hline \multirow{2}{*}{ Competency } & \multicolumn{3}{|c|}{ Importance } & \multicolumn{3}{c|}{ Performance } & \multirow{2}{*}{. } \\
\cline { 2 - 8 } & Mean & SD & N & Mean & SD & N & MWDS \\
\hline 4-H program management & 4.76 & .487 & 113 & 3.67 & .721 & 109 & 5.18 \\
\hline Communication & 4.65 & .531 & 113 & 3.68 & .663 & 110 & 4.51 \\
\hline Interpersonal characteristics & 4.78 & .417 & 113 & 3.96 & .732 & 109 & 3.91 \\
\hline Positive youth development & 4.78 & .458 & 113 & 4.03 & .630 & 109 & 3.58 \\
\hline Organization & 4.35 & .706 & 113 & 3.59 & .819 & 109 & 3.30 \\
\hline Education design and delivery & 4.09 & .830 & 113 & 3.38 & .755 & 109 & 2.90 \\
\hline
\end{tabular}

Note. MWDS = mean weighted discrepancy score

Table 4. 4-H Volunteers' Importance and Performance Scores

\begin{tabular}{|l|c|c|c|c|c|c|c|}
\hline \multirow{2}{*}{ Competency } & \multicolumn{4}{|c|}{ Importance } & \multicolumn{3}{c|}{ Performance } \\
\cline { 2 - 9 } & Mean & SD & N & Mean & SD & N & MWDS \\
\hline Organization & 4.50 & .629 & 4578 & 4.16 & .682 & 4536 & 1.53 \\
\hline 4-H program management & 4.64 & .575 & 4579 & 4.37 & .664 & 4536 & 1.25 \\
\hline Positive youth development & 4.76 & .467 & 4577 & 4.51 & .592 & 4537 & 1.19 \\
\hline Education design and delivery & 4.41 & .661 & 4582 & 4.19 & .681 & 4539 & 0.97 \\
\hline Communication & 4.56 & .624 & 4572 & 4.37 & .606 & 4538 & 0.86 \\
\hline Interpersonal characteristics & 4.76 & .461 & 4584 & 4.67 & .508 & 4542 & 0.42 \\
\hline
\end{tabular}

Note. MWDS = mean weighted discrepancy score 
Perceptions of Volunteer Competence

Table 5. 4-H Families' Importance and Performance Scores

\begin{tabular}{|l|c|c|c|c|c|c|c|}
\hline \multirow{2}{*}{ Competency } & \multicolumn{4}{|c|}{ Importance } & \multicolumn{3}{c|}{ Performance } \\
\cline { 2 - 8 } & Mean & SD & N & Mean & SD & N & MWDS \\
\hline Organization & 4.55 & .601 & 5304 & 4.00 & .939 & 5199 & 2.50 \\
\hline Positive youth development & 4.69 & .537 & 5301 & 4.18 & .913 & 5193 & 2.39 \\
\hline Communication & 4.57 & .614 & 5298 & 4.14 & .879 & 5200 & 1.96 \\
\hline Interpersonal characteristics & 4.73 & .496 & 5307 & 4.33 & .869 & 5198 & 1.89 \\
\hline Education design and delivery & 4.40 & .679 & 5305 & 4.01 & .939 & 5201 & 1.71 \\
\hline 4-H program management & 4.59 & .600 & 5307 & 4.26 & .843 & 5194 & 1.51 \\
\hline
\end{tabular}

Note. MWDS = mean weighted discrepancy score

Performance means were more varied across the three groups. Volunteer responses yielded the highest overall performance means, followed by family responses. Both families' and volunteers' performance scores averaged 4.00 or greater on a 5-point Likert-type scale. Families and volunteers generally reported volunteer performance to be good to very good across all six competencies. Professionals rated the performance of their volunteers the lowest among the three respondent groups; only the positive youth development competency yielded a mean of 4.00 or greater.

We also asked respondents their preferences about approaches for better equipping 4-H volunteers with desired knowledge, skills, and abilities (see Figure 2). Volunteers tended to select more self-directed approaches, such as online training modules and distribution of resources, rather than approaches led by or involving others (e.g., in-person trainings, observational visits). Some of the other ideas suggested by respondents included

- facilitating mentorship programs where older 4-H members are paired with younger 4-H members to guide them on project and exhibition requirements,

- creating a database of subject matter experts (e.g., photography, woodworking) who are willing to assist volunteers who have limited knowledge on a particular subject, and

- encouraging cross-county projects and exchanges for volunteers to expand their network and glean ideas from other counties. 
Figure 2. Percentage of Respondents Indicating Which Approaches Should be Used to Better Equip 4-H Volunteers with Desired Knowledge, Skills, and Abilities

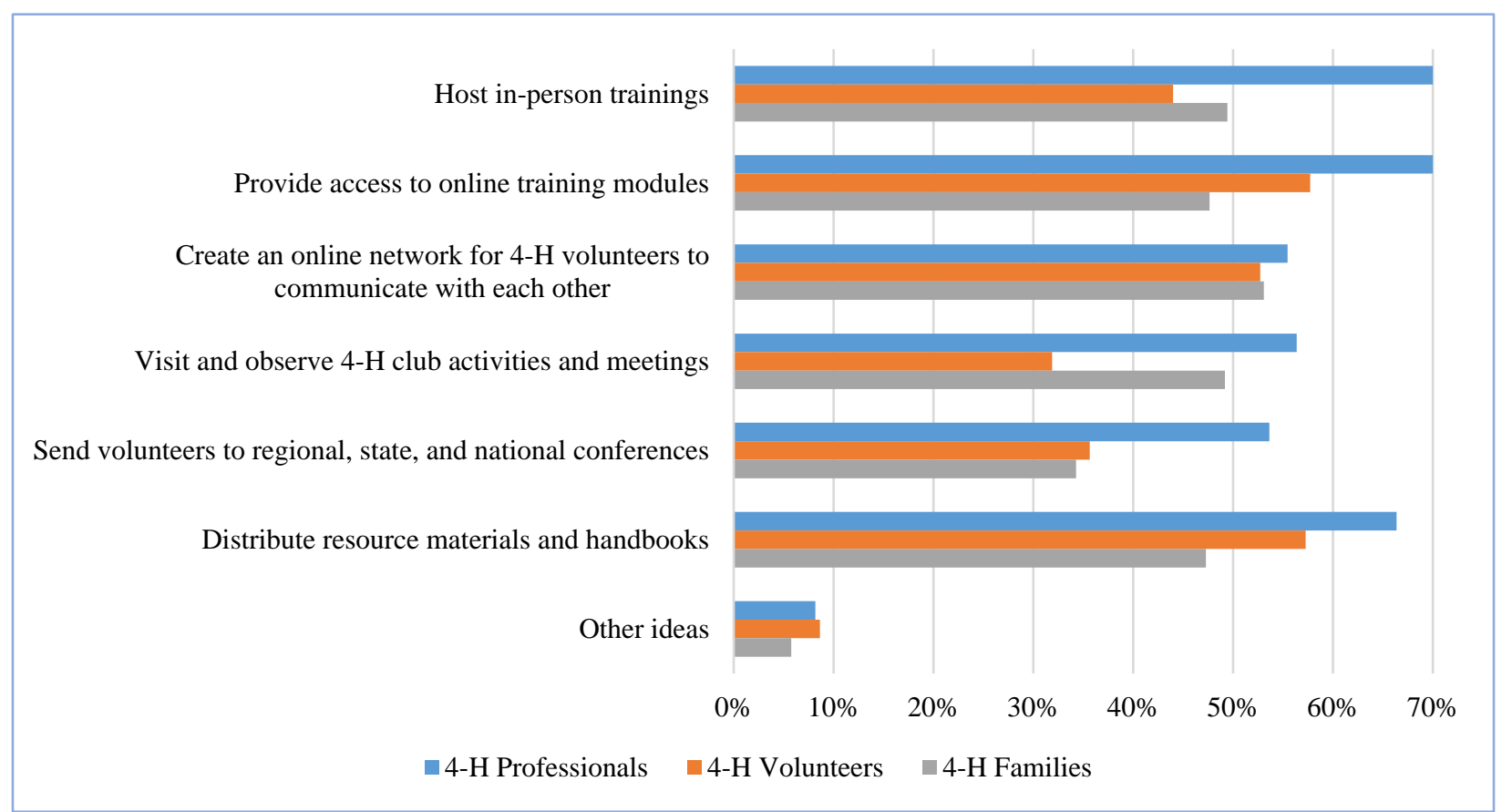

Note. Respondents were asked to select all that apply.

\section{Discussion and Conclusions}

Positive youth development is more likely to occur when youth engage with intentionally structured experiences. For some youth organizations, these experiences are facilitated by adult volunteers who are the point-of-service-the interface between youths and the organization. As a result, youth organizations must devote time and resources to an iterative process of recruiting, training, and evaluating their volunteer corps based on specific competencies needed to achieve the organization's intended outcomes.

The purpose of this study was to assess and compare the discrepancy between importance and ability to perform ratings against a set of six volunteer competencies in order to identify and prioritize training needs, along with the preferred modalities to deliver the training and resources. An online survey was emailed to Ohio county 4-H professionals, 4-H club volunteers, and families of $4-\mathrm{H}$ club members to collect data towards addressing this study's objectives.

Mean weighted discrepancy scores (MWDS) were computed from the importance and performance data to prioritize the competencies and compare respondent groups. A higher 


\section{Perceptions of Volunteer Competence}

score tends to indicate a competency that is deemed to be important for a volunteer to know or possess (i.e., high importance rating), but one which they do not adequately have or can perform based on desired metrics (i.e., low performance rating). We interpreted higher MWDS as the competencies we should prioritize.

\section{MWDS by Respondent Group}

All three groups probably responded to the survey with differing perspectives and priorities about how the 4-H organization best accomplishes its mission.

MWDS from volunteers were the lowest. We interpreted the scores as a positive signvolunteers thought the competencies were important and that they are generally performing them well. However, these results should be interpreted with caution. Volunteer data may be skewed higher toward how they believe they should be performing instead of capturing their actual performance. This phenomenon is defined as social desirability bias and causes misleading results (Fisher, 1993). Additionally, the volunteers who did respond may have been those who are higher performing and more motivated, which would have contributed to higher performance scores and lower MWDS.

4-H professionals reported the most discrepancy between the importance of the volunteer competencies and the volunteers' performance of the competencies. Their MWDS were the highest, indicating they believed the competencies are important, but that their volunteers' performance was only adequate to good. We interpreted these scores as a sign that more interventions are needed to bridge the gap between what volunteers should be able to do and how they are actually performing. However, these results should also be viewed with care. Professionals' performance scores may be influenced by the difficult situations they encounter and are tasked with solving across their volunteer program. They are responsible for mitigating risks and may feel burdened by volunteer policy requirements. They may have also focused on underperforming 4- $\mathrm{H}$ volunteers in their ratings, which would have skewed their scores downward, even though we asked them to evaluate their volunteers as a group.

Families' MWDS were between those of volunteers' and professionals' scores. Their scores help to balance the polarizing scores from the other two respondent groups. We believe family members' results may be a more accurate reflection of how volunteers are performing because they are an external audience and provide the closest perspective from our clients (i.e., youth) as indirect beneficiaries of 4- $\mathrm{H}$ programming through their youth. 


\section{Perceptions of Volunteer Competence}

\section{MWDS by Competency}

Both the organization and positive youth development (PYD) competencies were in the top three of families' and volunteers' MWDS when listed in descending order. Organization and PYD are at the core of 4-H's methodology. PYD is the 'why' or theory informing how 4-H is organized. Families may enroll their child, and people may volunteer their time because they believe 4-H aids in fostering youth who will make future contributions to society. Similarly, families and volunteers appear to prefer a structure that involves parents, addresses community needs, and is methodological-all components of the organization competency.

Professionals shared one common competency with families in the top three of MWDS when listed in descending order: communication. Volunteers have a considerable amount of autonomy with mentoring youth and facilitating activities. As a result, professionals and families may desire more frequent communication from volunteers to know what is going on and, especially, if a volunteer needs assistance.

Volunteers and professionals also shared one common competency in the top three of MWDS when listed in descending order: 4-H program management. Reporting procedures - from enrollment data to Internal Revenue Service financial reporting - and risk management compliance are constant duties asked of volunteers and managed by professionals. Respondents may view these systems as burdensome, confusing, and changing, resulting in less confidence in their abilities in this area. Families may be unaware of these requirements, resulting in a low MWDS for this competency from them. We believe the 4-H program management MWDS may decline in the future as professionals and volunteers get used to the current management systems. However, these systems may change, which will require ongoing communication and training.

\section{Implications}

The VRKC had not been reassessed for nearly 10 years and there was a lack of research related to it. Results from our initial study suggest that the competency taxonomy is still a valid framework to achieve 4-H's positive youth development goals. Adult volunteers, regardless of their organization affiliation, should be proficient in certain competencies and exhibit dispositions that are believed to catalyze positive youth development processes. Using the VRKC 


\section{Perceptions of Volunteer Competence}

taxonomy is one way to promote consistency across 4-H's broad geographic reach in order to achieve nationwide youth outcomes and impacts.

Our survey results suggest that future volunteer trainings and resources in our state should first be prioritized around the competency areas of organization, 4- $\mathrm{H}$ program management, PYD, and communication. A catalog of lesson plans and PowerPoints related to the aforementioned competency areas is already available through 4-H.org for 4-H professionals to use.

Professionals can adapt the content for their local situation in order to immediately begin focusing on the four competency areas. Table 6 displays the topical content available for $4-\mathrm{H}$ volunteer managers to download and use related to each of the prioritized areas.

Table 6. Lesson Plans and PowerPoints Available for 4-H Volunteer Managers to Train Volunteers on Topics Related to the Prioritized Competency Areas From this Study (National 4-H Council, n.d.-a)

\begin{tabular}{|c|c|}
\hline Competency taxonomy & Training topics \\
\hline Communication & $\begin{array}{l}\text { Speaking skills, listening skills, writing skills, non-verbal skills, } \\
\text { information delivery and dissemination, marketing and public } \\
\text { relations, and use of technology }\end{array}$ \\
\hline Organization & $\begin{array}{l}\text { Planning and organizing, time management, parent recruitment } \\
\text { and involvement, delegating tasks to parents, service to the } \\
\text { community, and marketing and publicity }\end{array}$ \\
\hline 4-H program management & $\begin{array}{l}\text { Organization and structure of extension, upholding the 4-H } \\
\text { mission, risk management/risk reduction, liability awareness and } \\
\text { reduction, club management, behavior management, record } \\
\text { keeping, financial management, computer skills }\end{array}$ \\
\hline $\begin{array}{l}\text { Positive youth development } \\
\text { (PYD) }\end{array}$ & $\begin{array}{l}\text { Developing life skills, leadership skills, understanding ages and } \\
\text { stages of youth development, empowerment of others, practicing } \\
\text { youth-adult partnerships, ability to motivate and encourage, } \\
\text { appreciating diversity }\end{array}$ \\
\hline
\end{tabular}

4-H professionals who reviewed the study results suggested that a user-friendly, on-demand, online database of resources be created for professionals to share with their volunteers organized around the competency themes. Their suggestion is also supported by volunteers who responded to our survey indicating they favored online trainings and networks. Transitioning to virtual education has been met with little resistance from volunteers in the past 


\section{Perceptions of Volunteer Competence}

and content is already available from other states (Hein et al., 2016). Yet, professionals still preferred interacting with their volunteers face-to-face at least once a year, particularly through annual orientations. Educators also recommended that professional development sessions related to the competencies be facilitated for them at bi-annual in-service meetings.

Results from our study are valuable for volunteer managers from other organizations to consider. Our results affirm the competency frameworks proposed by Yohalem (2003), Astroth et al. (2004), and the National AfterSchool Association (2011) because of similarities they share with the VRKC. Our discoveries may be helpful to youth organizations who use the aforementioned competency frameworks to inform their prioritization of future interventions, even though our data are specific to a geography (i.e., Ohio) and organization (i.e., 4-H).

We encourage other states and organizations to conduct similar surveys in order to create new or evaluate current volunteer competencies (Homan et al., 2017). Surveys are important tools for soliciting feedback from stakeholders to inform future strategic and programmatic decisions. Collecting baseline survey data, similar to what we did, can also help determine if interventions launched to target certain competencies are perceived as being effective by conducting followup surveys. For example, we would hope to see a lower MWDS for the PYD competency if we launch new trainings and resources around the PYD competency between now and when a future survey is conducted because of higher performance ratings. Future surveys should consider including perspectives from the youth organization's main "customer": youth. Additionally, future surveys should be conducted as volunteer bases "turn over."

The additional MWDS analysis can inform a prioritized development plan for volunteers and guide the design of orientations, trainings, and resources. The MWDS was borrowed from a needs assessment model designed by Borich (1980) for the formal education discipline. Our use of the model exhibits how it can be used as an interdisciplinary tool to combine, interpret, and compare two measures (e.g., importance and performance) from diverse groups to prioritize future programming.

Results from a similar survey could also assist organizations with crafting strategic communication and marketing messages. For example, families' data revealed organization and PYD as their top two competencies based on MWDS. We believe this could be a manifestation of why they value their youths' involvement in 4-H, along with their rationale for having their youth enrolled. These results reveal to us that families want their youth involved in a structured 


\section{Perceptions of Volunteer Competence}

program using PYD principles. We can use these insights in future recruitment messages aimed at increasing the membership of our organization.

While we designed this study to address shortcomings of the VRKC, our study is not able to identify how adults exhibiting specific competencies affect youth acquiring desired, developmental assets. Our stakeholders voiced their opinions of the competencies they believe our volunteers should possess. We value their opinions and will consider them as we design future volunteer management initiatives. Yet, we still lack the causal evidence informing us as to what knowledge, skills, and abilities of youth workers and adult volunteers are most likely to encourage specific youth outcomes. For example, does an adult who is considered competent in program management affect how youth acquire the assets of character or connection? Obtaining this evidence will require a much more robust and lengthy research design, but it is what we need and hope to ascertain someday to better inform our volunteer competency framework.

\section{References}

Albright, M. B., \& Ferrari, T. M. (2010). "Push" and "pull" a qualitative study of factors that contribute to older youth leaving the 4-H program. Journal of Youth Development, 5(3), 55-74. https://doi.org/10.5195/jyd.2010.209

Astroth, K. A., Garza, P., \& Taylor, B. (2004). Getting down to business: Defining competencies for entrylevel youth workers. New Directions for Youth Development, 104, 25-37.

\section{https://doi.org/10.1002/yd.96}

Benson, P. L. (2007). Developmental assets: An overview of theory, research, and practice. In R. Silbereisen \& R. Lerner (Eds.), Approaches to Positive Youth Development (pp. 33-58). SAGE.

Borich, G. D. (1980). A needs assessment model for conducting follow-up studies. Journal of Teacher Education, 31(3), 39-42.

Culp, K., McKee, R. K., \& Nestor, P. (2007). Identifying volunteer core competencies: Regional differences. Journal of Extension, 45(6). http://www.joe.org/joe/2007december/a3p.shtml

Dillman, D. A. (2000). Mail and internet surveys. John Wiley \& Sons.

Eccles, J. \& Gootman, J. (Eds.). (2002). Community programs to promote youth development. National Academy Press.

Fisher, R. J. (1993). Social desirability bias and the validity of indirect questioning. Journal of Consumer Research, 20, 303-315. https://doi.org/10.1086/209351 
Journal of Youth Development | http://jyd.pitt.edu/ | Vol. 15 Issue 4 DOI 10.5195/jyd.2020.742

Perceptions of Volunteer Competence

Fogarty, K., Terry, B., Pracht, D., \& Jordan, J. (2009). Organizational supports and youth life skill development: Adult volunteers as mentors, managers and "mediators." Journal of Youth Development, 4(4). https://doi.org/10.5195/iyd.2009.239

4-H National Headquarters. (2017). Growing together: 4-H professional, research, knowledge and competencies 2017. https://nifa.usda.gov/sites/default/files/resources/4-H-PRKC-2017-quide.pdf

Guerra, N. G., \& Bradshaw, C. P. (2008). Linking the prevention of problem behaviors and positive youth development: Core competencies for positive youth development and risk prevention. In N. G. Guerra \& C. P. Bradshaw (Eds.), Core competencies to prevent problem behaviors and promote positive youth development. New Directions for Child and Adolescent Development, 122, 1-17.

Hein, W., White, T., \& Williams, J. (2016). Successful use of Extension and online training modules in mandatory biennial volunteer recertification. Journal of Youth Development, 11(3).

\section{https://doi.org/10.5195/jyd.2016.464}

Hobbs, S. (2012). The latest approach to volunteer recruitment. In T. D. Connors (Ed.), The volunteer management handbook: Leadership strategies for success (pp. 203-225). John Wiley \& Sons.

Homan, D. M., Bloir, K. L., \& Epley, H. K. (2017). Evaluating volunteer competencies to achieve organizational goals. International Journal of Volunteer Administration, 32(2), 35-49. https://www.ijova.org/docs/Full Issue November 2017 (1).pdf

Lerner, R. M., Lerner, J. V., \& Colleagues. (2013). The positive development of youth: Comprehensive findings from the 4-H study of positive youth development. National 4-H Council.

Miller, L. E., \& Smith, K. L. (1983). Handling nonresponse issues. Journal of Extension, 21(5). https://www.joe.org/joe/1983september/83-5-a7.pdf

National AfterSchool Association. (2011). Core knowledge and competencies for afterschool and youth development professionals. https://naaweb.org/resources/core-competencies

National 4-H Council. (n.d.-a). Volunteer research knowledge and competency lesson plans. Author. https://4-h.org/professionals/professional-development/volunteer-development/\#!vrkc-modellesson-plans

National 4-H Council. (n.d.-b). Volunteer research knowledge and competency taxonomy for 4-H youth development. Author.

Padgett, D. K. (2008). Qualitative methods in social work research-second edition. SAGE.

Radhakrishna, R., \& Doamekpor, P. (2008). Strategies for generalizing findings in survey research. Journal of Extension, 46(2). https://www.joe.org/joe/2008april/tt1.php

Radhakrishna, R., \& Ewing, J. C. (2011). Relationships between 4-H volunteer leader competencies and skills youth learn in 4-H programs. Journal of Extension, 49(4). https://www.joe.org/joe/2011august/rb2.php 
Journal of Youth Development | http://jyd.pitt.edu/ | Vol. 15 Issue 4 DOI 10.5195/jyd.2020.742 Perceptions of Volunteer Competence

Shippmann, J. S., Ash, R. A., Battista, M., Carr, L., Eyde, L. D., Hesketh, B., Kehoe, J., Pearlman, K., Prien, E. P., \& Sanchez, J. I. (2000). The practice of competency modeling. Personne/ Psychology, 53, 703-740.

Singletary, L., Smith, M., \& Evans, W. P. (2006). Self-perceived 4-H leader competencies and their relation to the skills youth learn through $4-\mathrm{H}$ youth development programs. Journal of Extension, 44(4). http://www.joe.org/joe/2006august/rb2.php

Smith, C., Akiva, T., Arrieux, D., \& Jones, M. M. (2006). Improving quality at the point of service. In D.A. Blyth \& J.A. Walker (Eds.), Rethinking programs for youth in the middle years. New Directions for Student Leadership, 112, 93-108.

Yohalem, N. (2003). Adults who make a difference: Identifying the skills and characteristics of successful youth workers. Community youth development: Programs, policies, and practices, 358-372. 